\title{
Ground deformation occurring in the city of Auckland, New Zealand, and observed by Envisat interferometric synthetic aperture radar during 2003-2007
}

\author{
Sergey Samsonov, ${ }^{1,2}$ Kristy Tiampo, ${ }^{2}$ Pablo J. González, ${ }^{3}$ Vernon Manville, ${ }^{4,5}$ \\ and Gill Jolly ${ }^{4}$
}

Received 22 July 2009; revised 21 April 2010; accepted 4 May 2010; published 25 August 2010.

[1] In this study we present modeling results derived from ground deformation observed in the Auckland Volcanic Field (AVF) by the C-band Envisat Synthetic Aperture Radar. Auckland, the largest city in New Zealand with a current population of over one million, coincides with the AVF, which comprises about 50 individual, largely monogenetic, basaltic volcanoes distributed across a total area of $360 \mathrm{~km}^{2}$. The most recent and largest eruption there occurred 600 years ago. While it is anticipated that the chance of any existing volcano reawakening is very low, a new volcano could be created at any time in a new location within the field. The aim of this work is to evaluate the feasibility of interferometric synthetic aperture radar (InSAR) for mapping ground deformation associated with magma ascent, which would be a likely precursor to the onset of volcanic activity. For this study we acquired and processed 23 single look complex (SLC) images from the Envisat satellite (Track 151, Frame 6442, IS2, VV) spanning from July 2003 until November 2007. All possible combinations of differential interferograms were created. Stacking, Small Baseline Subset (SBAS) and Permanent Scatterers (PS) processing algorithms were used to determine spatial and temporal patterns of surface deformation as well as their average rates. A number of localized deformation regions were consistently observed by all three techniques. Due to a lack of evidence pointing toward a relationship with volcanic or tectonic sources it was assumed that they are produced by groundwater withdrawal and recharge. Three largest regions of subsidence (S1-S3) and also three largest regions of uplift (U1-U3) were modeled with the derivative-free simplex algorithms for location, depth and source volume change using a Mogi point source approximation. The results show that InSAR is a viable technique capable of detecting the scale, rate and spatial distribution of precursory deformation that would likely be associated with resumption of volcanic activity in the Auckland urban area.

Citation: Samsonov, S., K. Tiampo, P. J. González, V. Manville, and G. Jolly (2010), Ground deformation occurring in the city of Auckland, New Zealand, and observed by Envisat interferometric synthetic aperture radar during 2003-2007,

J. Geophys. Res., 115, B08410, doi:10.1029/2009JB006806.

\section{Introduction}

[2] One of the key challenges faced by volcanologists is the improvement of our understanding of when and where the next eruption will occur, particularly in the case of quiescent volcanic centers which may have been dormant for a very long time and currently exhibit no signs of unusual activity.

\footnotetext{
${ }^{1}$ GNS Science, Lower Hutt, New Zealand.

${ }^{2}$ Department of Earth Sciences, University of Western Ontario, London, Ontario, Canada.

${ }^{3}$ Facultad de Matemáticas, Instituto de Astronomia y Geodesia, CSICUCM, Madrid, Spain.

${ }^{4}$ Wairakei Research Center, GNS Science, Taupo, New Zealand.

${ }^{5}$ School of Earth and Environment, University of Leeds, Leeds, UK.

Copyright 2010 by the American Geophysical Union. 0148-0227/10/2009JB006806
}

At such volcanoes, eruptions are infrequent on human timescales, and the associated hazards may be poorly acknowledged, inviting encroachment by populations and increasing the risk of future disasters. Recognition that a volcano is merely the surface expression of a deep-seated cyclical magmatic process enables the use of three different monitoring techniques to detect possible indicators of deep and hence long-term unrest: earthquakes [McNutt, 1996]; magmatic $\mathrm{CO}_{2}$ flux rates [Salazar et al., 2000; Hernandez et al., 2000]; and aseismic surface deformation. A range of geodetic tools can be used for monitoring surface deformations including interferometric synthetic aperture radar (InSAR), large-aperture GPS surveys, microgravity surveys, dense continuous GPS arrays, strainmeters and tiltmeters [Dzurisin, 2003]. InSAR has become an important part of volcano monitoring worldwide since its first application at Mount 


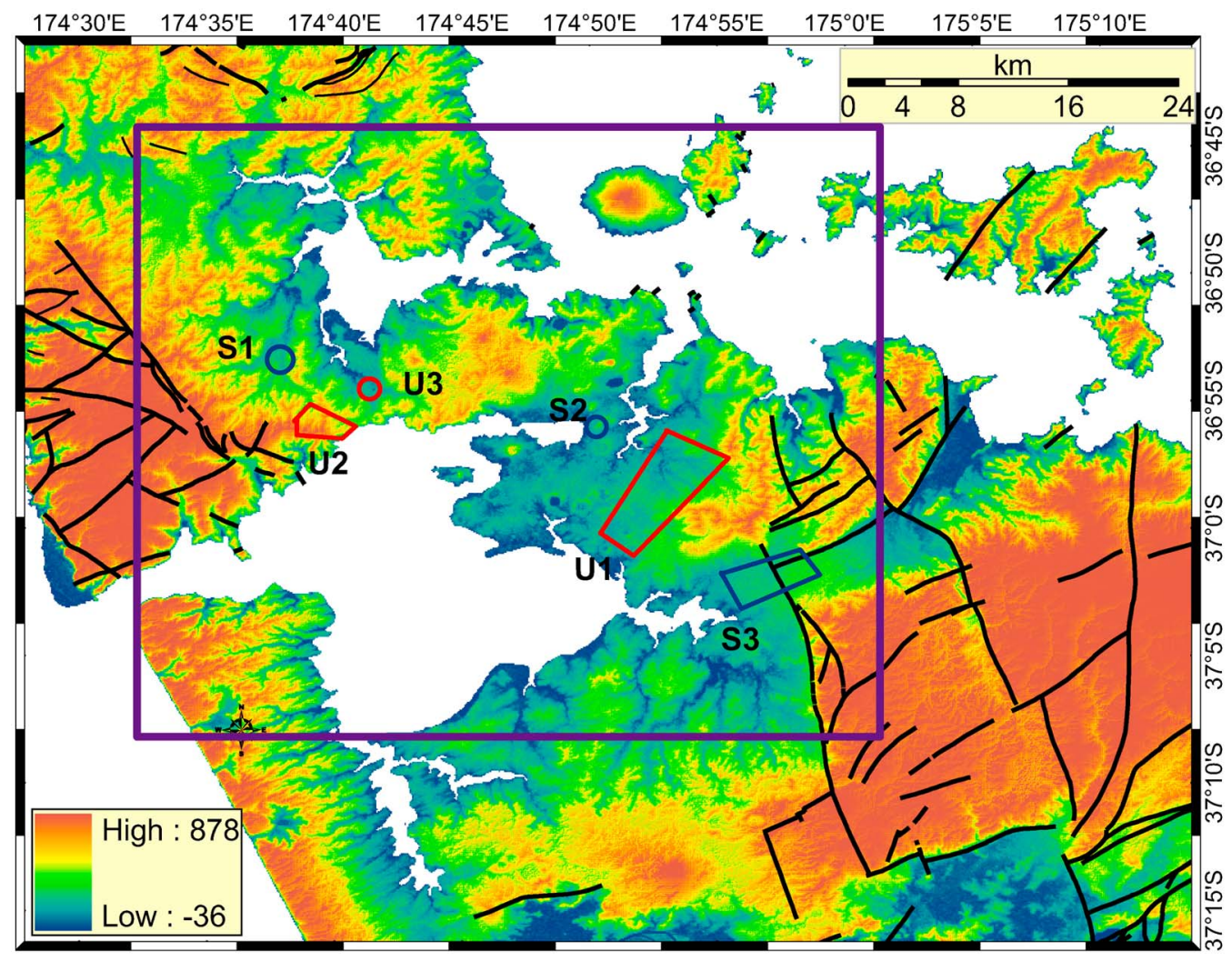

Figure 1. Shaded relief DEM (in meters) of the Auckland Volcanic Field (inside rectangle) and outlines of observed ground deformation (uplifts U1-U3 and subsidence U1-U3). Known faults are plotted as black lines.

Etna [Massonnet et al., 1995]. The technique relies on combining phase information from two or more SAR images of the same area captured at different times from a similar vantage point to produce an interferogram [Massonnet and Feigl, 1998]. This shows range changes in the view direction between the satellite-borne instrument and the Earth's surface, and can be further processed with a topographic model to image ground deformation at a horizontal resolution of tens of meters over areas of $\sim 100 \times 100 \mathrm{~km}$ with $\mathrm{cm}$ to sub-cm vertical precision under ideal conditions. The broad areal extent and high vertical resolution of spaceborne InSAR is particularly valuable for study of deformation signals at volcanic fields and calderas [e.g., Lu et al., 2000; Kwoun et al., 2006] where there is considerable uncertainty about where activity may be focused or at complex volcano-tectonic systems characterized by lateral as well as vertical magma migration [e.g., Lu et al., 2002].

\subsection{Auckland Volcanic Field}

[3] The Auckland Volcanic Field (AVF, Figure 1) comprises 49 small basaltic volcanoes spread across an elliptical area of $\sim 360 \mathrm{~km}^{2}$ [Allen and Smith, 1994], which have erupted through a $\sim 500 \mathrm{~m}$ thick cover of Miocene and PlioPleistocene marine sedimentary rocks that overlie faulted Mesozoic basement [Edbrooke et al., 2003]. The field has been active for circa 140,000 years, producing $\sim 3.4 \mathrm{~km}^{3}$ (Dense Rock Equivalent, DRE) of basaltic eruption products [Kermode, 1992; Smith and Allen, 1993], with the most recent eruption occurring only 600-800 years ago. Eruptions have ranged in style from phreatomagmatic (producing tuff rings and maars) to magmatic (forming scoria cones and lava flows), with individual vents often generating several styles of activity [Allen and Smith, 1994]. Each vent typically erupts a single batch of magma during a discrete, relatively shortlived eruption episode that lasts for less than ten years, although there is increasing evidence for episodes that involve eruption of a magma batch at multiple adjacent vents over periods of centuries [Allen and Smith, 1994; Cassidy et al., 1999; Cassidy and Locke, 2004]. Most centers have eruptive volumes less than $0.01 \mathrm{~km}^{3}$ (DRE), six have volumes of $0.05-0.35 \mathrm{~km}^{3}$, while the most recent eruption, Rangitoto in circa 1350 A.D., produced approximately $2 \mathrm{~km}^{3}$ of magma (59\% of the AVF total). The source of the basaltic magma is thought to lie at depths of $70-140 \mathrm{~km}$, based on mantle xenoliths in erupted material [Cassidy et al., 1986], U-Th isotopes [Huang et al., 1997], and seismic detection of a low velocity layer [Horspool et al., 2006]. The presence of mantle xenoliths was used to estimate a magma ascent rate of 1 $10 \mathrm{~cm} / \mathrm{s}$ [Cassidy et al., 1986], implying rise from a depth of $100 \mathrm{~km}$ in 10-100 days. Historically low levels of seismicity in the area suggest that, by analogy with other monogenetic basalt fields, seismic precursors could occur as soon as a few days to 2 weeks before an eruption [Sherburn et al., 2007].

[4] Further eruptions from the AVF are likely, with serious social and economic consequences for the city of Auckland [Johnston et al., 1997; Paton et al., 1999; Magill and Blong, 
Table 1. Envisat ASAR Images Spanning 2003-2007 Used in This Study and the Time Span in Days From the First Acquisition ${ }^{\mathrm{a}}$

\begin{tabular}{ccc}
\hline Image & Time & Span \\
\hline 1 & 20030718 & 0 \\
2 & 20030926 & 70 \\
3 & 20031031 & 105 \\
4 & 20031205 & 140 \\
5 & 20040109 & 175 \\
6 & 20040213 & 210 \\
7 & 20040319 & 245 \\
8 & 20040423 & 280 \\
9 & 20040528 & 315 \\
10 & 20040702 & 350 \\
11 & 20040910 & 420 \\
12 & 20041015 & 455 \\
13 & 20041224 & 525 \\
14 & 20050408 & 630 \\
15 & 20050513 & 665 \\
16 & 20050617 & 700 \\
17 & 20050722 & 735 \\
18 & 20050930 & 805 \\
19 & 20051104 & 840 \\
20 & 20051209 & 875 \\
21 & 20060324 & 980 \\
22 & 20060602 & 1050 \\
23 & 20060811 & 1120 \\
24 & 20060915 & 1155 \\
25 & 20070309 & 1330 \\
26 & 20071109 & 1575 \\
\hline
\end{tabular}

${ }^{\mathrm{a}}$ The image acquired on 20031205 had a large orbital error and was removed from further processing. Time is given in YYYYMMDD format.

2005; Houghton et al., 2006], which, with a population of one million is New Zealand's largest urban area and is almost exactly coincident with the field.

[5] Basement faults form an orthogonal pattern, trending both northeast-southwest and northwest-southeast. Where volcanic vents cluster, they are sometimes aligned northeastsouthwest, possibly reflecting a structural control. The thickness of the seismic crust beneath the AVF is estimated at approximately $25 \pm 2 \mathrm{~km}$ [Stern et al., 1987; Horspool et al., 2006], while the brittle-ductile transition lies at $\sim 15-20 \mathrm{~km}$ [Sherburn et al., 2007].

[6] The AVF is currently monitored by the Auckland Volcano-Seismic Network (AVSN), consisting of five telemetered, vertical-component, short-period $(1 \mathrm{~Hz})$ seismographs, four of which are situated in shallow $(10-30 \mathrm{~m})$ boreholes to reduce ambient noise, and four strong motion sensors. Data are digitized at $100 \mathrm{~Hz}$ and transmitted to GNS Science in Taupo and Wellington for near-real-time analysis [Sherburn et al., 2007]. Based on seismic precursors to eruptions from historically active volcanic fields, instrumental detection of an impending eruption could occur between 9 and 14 days before surface activity as ascending magma interacts with the base of the crust to produce deep long period earthquakes, although events would need to be much shallower $(\sim 5 \mathrm{~km})$ before their epicentral locations could be used to constrain a possible vent location [Sherburn et al., 2007]. Ground deformation monitoring would be difficult to apply in the AVF because of its large areal extent, but dense kinematic GPS measurements could be made following the onset of seismicity [Miller et al., 2001]. InSAR techniques are more promising because of their large areal coverage, while the abundance of paved surfaces in the city reduces decorrelation and maximizes coherence [Massonnet and
Feigl, 1998]. The difficulty with InSAR is the low frequency of observations, with a 35 day interval between Envisat overflights, however, it is expected that the revisit time will be significantly shorten in the future (e.g., satellite constellation). In this work we aim to evaluate the feasibility of InSAR for mapping ground deformation in the Auckland Volcanic Field associated with magma ascent that would be a likely precursor to the onset of volcanic activity.

\section{Data and Processing Techniques}

[7] In order to study ground deformation in the Auckland Volcanic Field we acquired and processed 26 Envisat ASAR (Track 151, Frame 6442, IS2, VV) images spanning from 18 July 2003 until 9 November 2007 (Table 1). The GAMMA interferometric processor [Wegmuller and Werner, 1997] was used to compute differential interferograms. Precise orbits from the European Space Agency and Delft University were used to estimate orbital parameters and the $90 \mathrm{~m}$ SRTM Digital Elevation Model (DEM) [Farr and Kobrick, 2000] was used to remove the topographic phase. Initially all images were re-sampled to a single master image acquired on 17 June 2005 (20050617), $2 \times 10$ multilooking to a resolution $20 \times$ $40 \mathrm{~m}$ (range $\mathrm{x}$ azimuth) was applied and then differential interferograms were calculated. All interferograms with slave images acquired on 20031205 were removed from further processing because of a large error in the estimation of orbital parameters. Phase unwrapping was performed using the Minimum Cost Flow algorithm [Costantini, 1998], and least squares estimation of interferometric baselines was performed in order to correct for minor errors in estimation of orbital parameters. Computed differential interferograms were then used for advanced processing and final results were geocoded and plotted.

[8] Initial interpretation of 117 differential interferograms revealed the presence of significant tropospheric noise on most interferograms and the absence of a large deformation signal. In order to improve the quality of these results we applied three advanced processing techniques: stacking, Small Baseline Subset (SBAS) and Permanent Scatterers (PS). Since the atmospheric noise is random in time and space while ground deformation is consistent, advanced processing by any of the proposed techniques decreases the contribution of random noise, increasing the accuracy of ground deformation measurements [Samsonov, 2010].

\subsection{Stacking}

[9] For stacking analysis [Wright et al., 2004; Sandwell and Price, 1998] it was initially assumed that the average rate of deformation across the whole region is zero. All 117 interferograms with baselines less than $400 \mathrm{~m}$ were shifted to meet this criterion and an initial stack was calculated. Second, a stable region $(16 \times 16$ pixels $)$ was chosen and the stack with corresponding errors was recalculated from interferograms adjusted against this reference point. Multiple reference points were tested but results did not vary significantly.

\subsection{Small Baseline Subset}

[10] For SBAS analysis we used the methodology provided by Berardino et al. [2002] and Samsonov [2010]. The processing code for this technique was written in MATLAB 


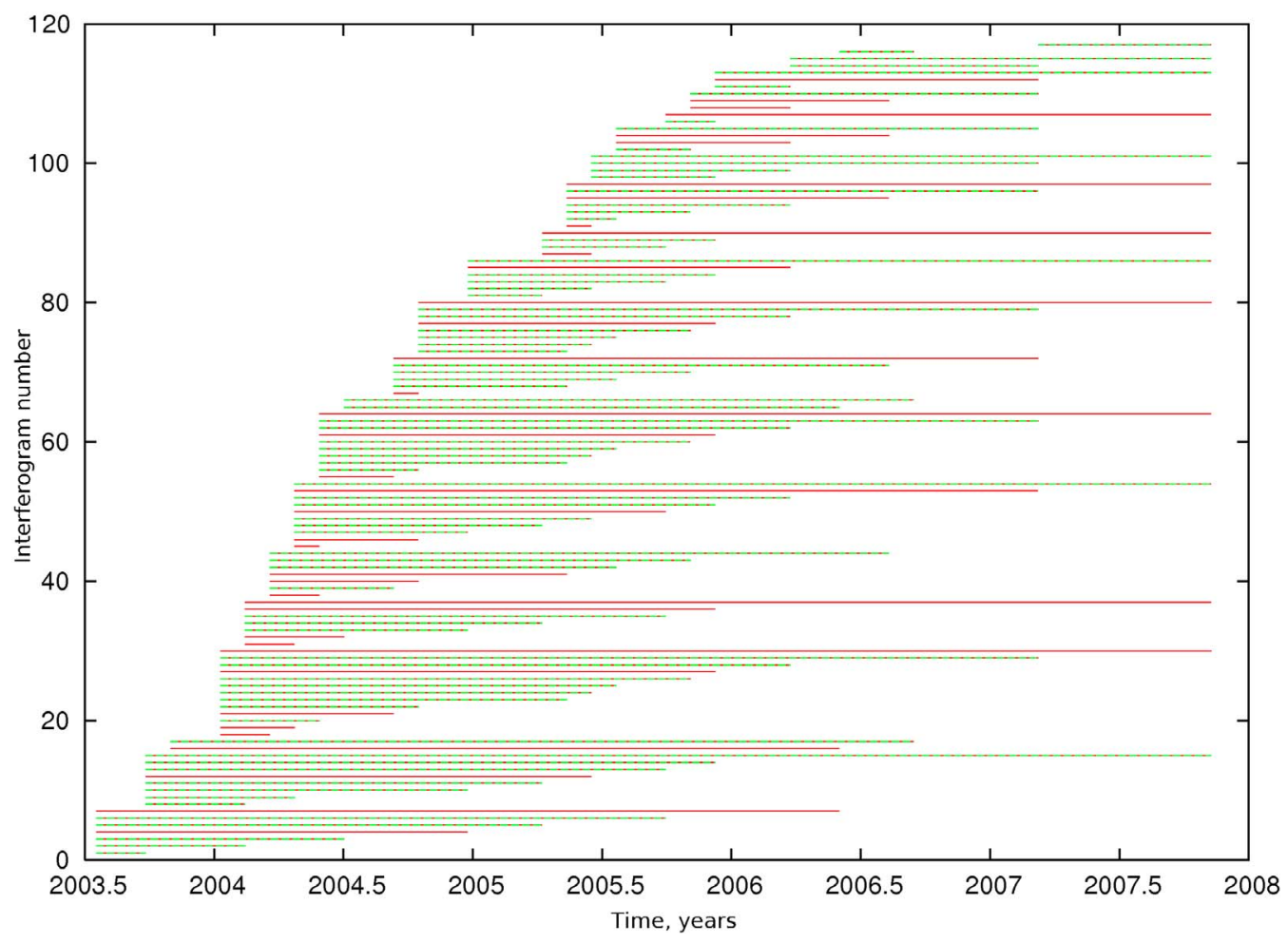

Figure 2. Differential interferograms used in this study. In red and green (117) interferograms with $B p<$ $400 \mathrm{~m}$ that were used for stacking and SBAS processing. In green (78) interferograms with perpendicular baseline $B p<300 \mathrm{~m}$ employed in PS processing only.

because of the simplicity of the matrix computation. The same 117 interferograms $(B p<400 \mathrm{~m})$ were used to create a set of 117 equations with 25 unknown velocities $(v)$. The solution was calculated only for pixels that were coherent $(\gamma>0.3$, where $\gamma$ is a magnitude of cross-correlation between master and slave images calculated for each pixel) on all interferograms. The displacement time series were reconstructed from known velocities provided by SBAS and time intervals [Kwoun et al., 2006] and linear regression was performed in order to estimate the average linear deformation rates for the 2003-2007 period. RMS errors were also calculated for each pixel as an average deviation from the linear trend.

\subsection{Permanent Scatterers}

[11] Permanent scatterers [Ferretti et al., 2001, 2004] were identified as pixels with the dispersion of intensity less than 0.25 , and further processing was performed on permanent scatterers only. A single master was chosen (20050617) and 24 interferograms were calculated. However, a few interferograms had large perpendicular baselines and, therefore, could not be visually examined due to the $2 \pi$ ambiguity in unwrapping. Several other interferograms had a very strong residual orbital signal. These were removed from the consequent analysis. Regression analysis then was performed to estimate linear rates of deformation using baseline and time dependence data of the interferometric phases. The deviation of the phase from the regression fit was used as a goodnessof-fit parameter and only certain pixels with lower deviation than a set threshold value were selected. Various threshold values were tested experimentally and the best value based on visual observation of the results was chosen. However, the analysis of the residuals even for the best case revealed multiple errors in unwrapping caused by large atmospheric noise and errors in the DEM.

[12] Instead, the processing algorithm was slightly modified. Only interferograms with perpendicular baselines less than 300 meters were selected and Ground Control Pointscorrected orbital parameters were copied from similar pairs used in stacking and SBAS processing. Then the topographic phase was removed using the SRTM DEM, followed by phase unwrapping using a Minimum Cost Flow algorithm [Costantini, 1998]. Finally, seventy-eight unwrapped differential interferograms with corrected orbital parameters were used in the regression analysis for estimation of linear deformation rates with corresponding errors.

\section{Results}

[13] The results of the interferometric processing consist of 117 differential interferograms used in stacking and SBAS processing and 78 differential interferograms used in PS processing (Figure 2), average linear deformation rates calculated with stacking, SBAS and PS techniques with corresponding errors, and time series calculated with SBAS and PS techniques. Initial interpretation of 117 interferograms revealed a significant amount of tropospheric noise and absence of a large deformation signal. Some deformation signal retrospectively was observed on a few interferograms; however; during the initial analysis it was interpreted as noise. 

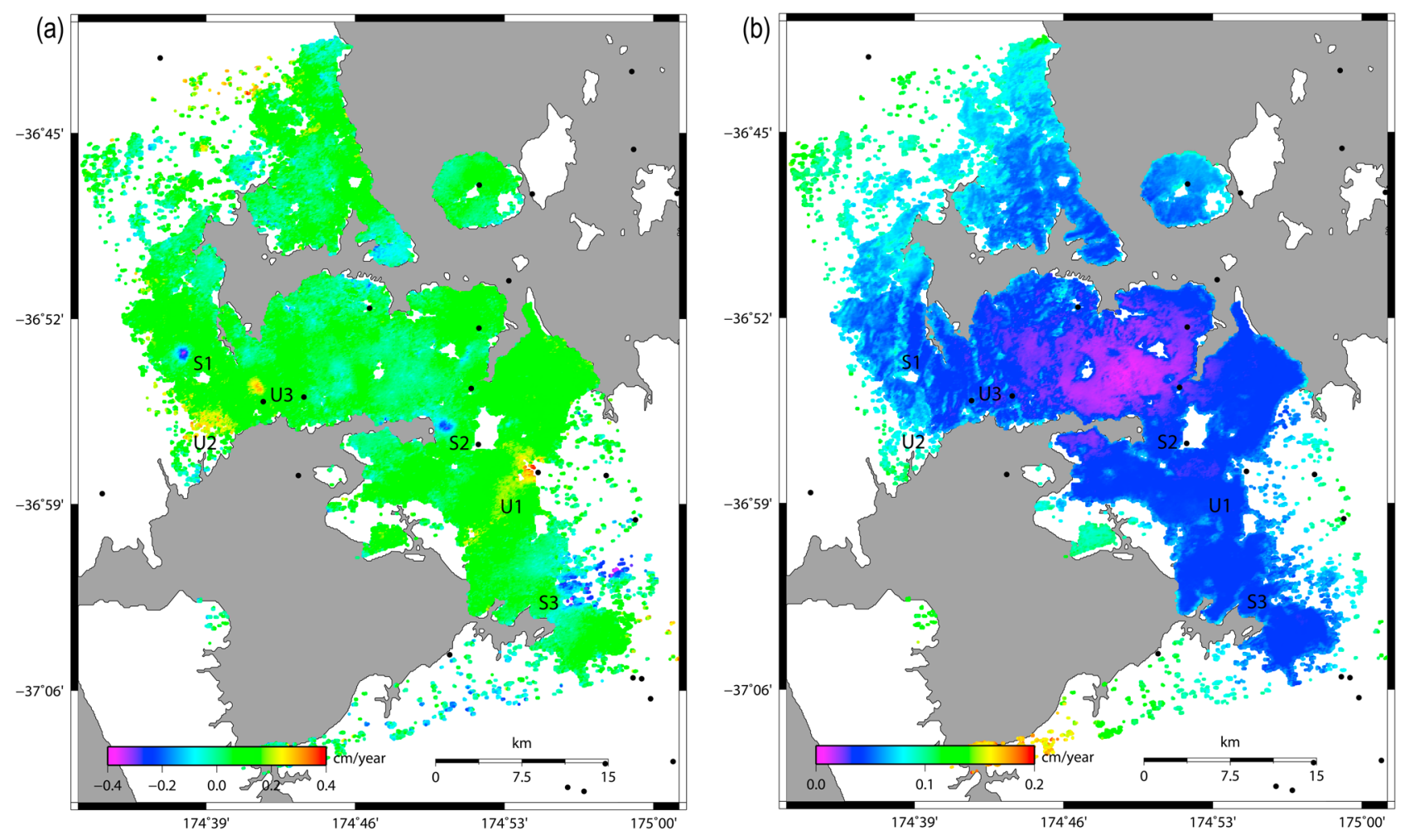

Figure 3. (a) Stack with (b) corresponding errors calculated from 117 differential interferograms with $B p<$ $400 \mathrm{~m}$ acquired by Envisat satellite between 2003 and 2007. Stack was calculated only for pixels that were coherent on 110 out of 117 interferograms. Areas of subsidence (in blue) and uplift (in yellow-orange) are clearly visible. Earthquakes with maximum magnitude between 1.7 and 3.0, occurring between 1998 and the present are shown as black dots. There was no seismic activity observed on land during 2003-2008 in proximity to observed deformation regions.

\subsection{Stacking}

[14] Results of stacking are presented in Figure 3a with corresponding errors in Figure $3 \mathrm{~b}$. Epicenters of historic earthquakes (prior to 2003) are plotted as black dots. Only the urban area of the Auckland Volcanic Field (AVF) is coherent on most interferograms. Overall the whole region is stable within $1-2 \mathrm{~mm} / \mathrm{yr}$ and no large scale deformation signal is observed. However, a few regions of localized subsidence and uplift are apparent. Three well defined areas of subsidence are observed with deformation rates of about $-0.4 \mathrm{~cm} / \mathrm{yr}$ located at S1:(S36.89, E174.63), S2: (S36.94, E174.84) and S3:(S37.03, E174.93). The two smallest subsidence signals (S1 and S2) are only about $1 \mathrm{~km}$ in diameter. The larger subsidence located at the southern part of the map (S3) is approximately $5 \mathrm{~km}$ in diameter. Three large uplifts are also observed in the region located at U1:(S36.98, E174.88), U2:(S36.94, E174.66) and U3:(S36.91, E174.69) with the rate of deformation approximately $0.35-0.4 \mathrm{~cm} / \mathrm{yr}$. The uplift U1 is the largest with dimensions 4 by $8 \mathrm{~km}$. It has a well defined southwest to northeast trend with an apparent maximum at the northwest corner. Uplift U2 is approximately $3 \mathrm{~km}$ in diameter and only partially visible due to decorrelation. Uplift U3 is smaller, about $1 \mathrm{~km}$ in diameter.

[15] Standard deviation of the stacked deformation rates ranges from about 0 to $0.2 \mathrm{~cm} / \mathrm{yr}$, reaching a minimum value at the region chosen as a reference and increasing with dis- tance from that point. This behavior is anticipated because of residual orbital and other long wavelength errors. A few disconnected regions have larger error than the main area due to errors in phase unwrapping.

\subsection{Small Baseline Subset}

[16] SBAS deformation rates are presented in Figure 4a, and in general, they are in good agreement with the stacking results. All three region of subsidence (S1-S3) are still clearly visible with approximately the same rates of $-0.4 \mathrm{~cm} / \mathrm{yr}$. However, some scattered subsidence is also observed in the northern part of the image. Uplift U1 is visible but with smaller rates of $\sim 0.2 \mathrm{~cm} / \mathrm{yr}$, and uplifts $\mathrm{U} 2$ and $\mathrm{U} 3$ are approximately the same as on the stacking image. The error was calculated as an RMS deviation from linear trend [Press et al., 2007] and its value does not vary significantly within the image, excluding a few disconnected area probably affected by errors in phase unwrapping.

[17] Results of time series analysis performed using the SBAS technique [e.g., Kwoun et al., 2006] without spatial averaging or temporal filtering area are presented in Figure 5. Rates of deformation were calculated for 25 temporal points spanning 2003-2007 and then cumulative deformation was reconstructed by integration. The time series analysis reveals deformation with a similar overall trend pattern for most sources except subsidence S1, which shows some sign of reversal after April 2006. Large fluctuations are observed on 

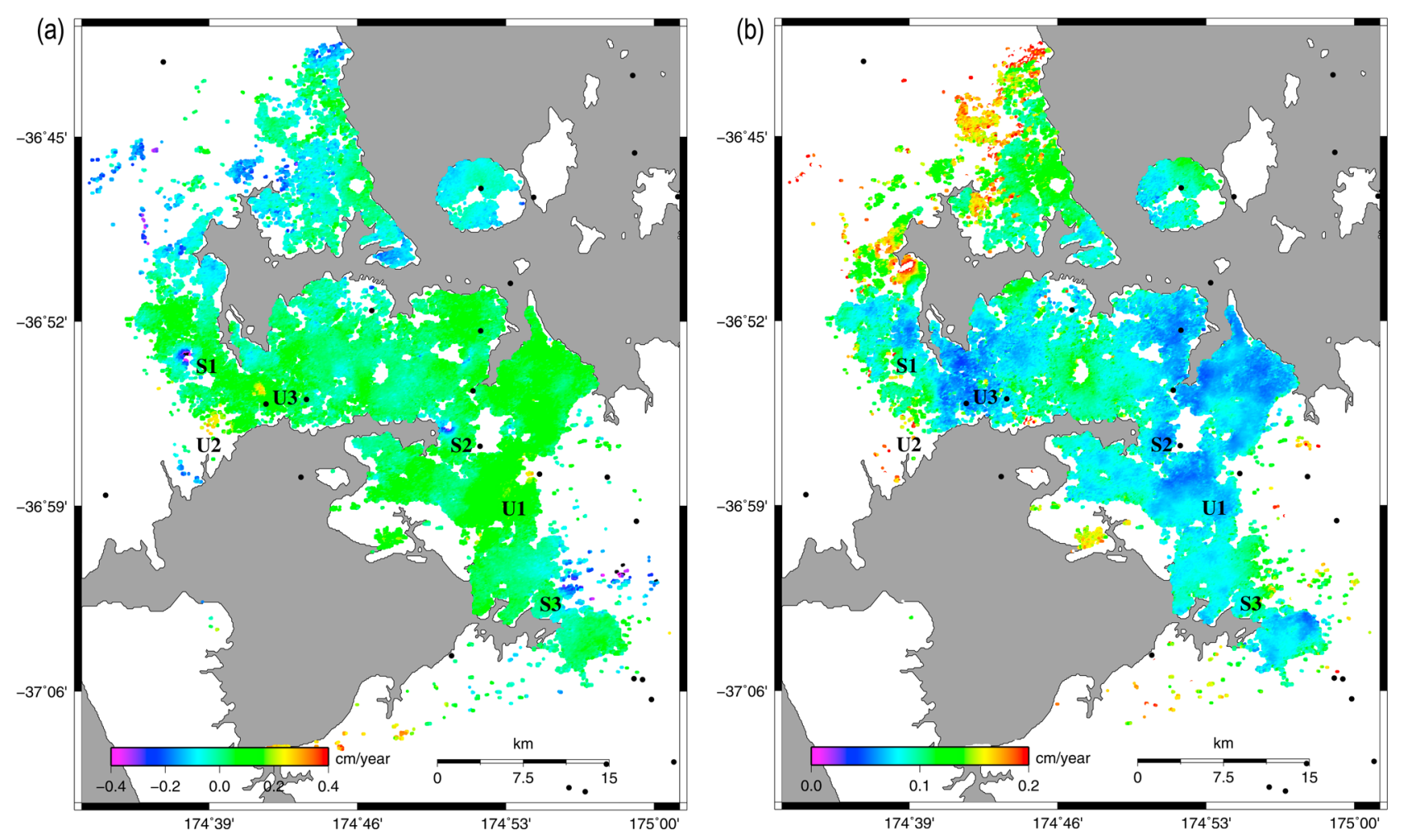

Figure 4. (a) Linear rates of deformation calculated from 117 differential interferograms with $B p<$ $400 \mathrm{~m}$ acquired by the Envisat satellite between 2003 and 2007 using Small Baseline Subset technique. The calculations were done only for pixels that were coherent on all 117 interferograms. DEM error correction was performed. (b) RMS error shows the deviation from a linear trend. Earthquakes with maximum magnitude between 1.7 and 3.0 occurring between 1998 and the present are shown as black dots.

all six time series, which are probably caused by seasonal signal or tropospheric noise.

\subsection{Permanent Scatterers}

[18] PS deformation rates are presented in Figure 6a with corresponding errors in Figure 6b. In general agreement between this and previous results is reasonable. Subsidence S1-S3 are still clearly visible with approximately the same rates as above. The uplifts U1 and U2 are hard to distinguish from noise but uplift U3 is somewhat apparent. Standard deviation ranges from about 0 to $0.2 \mathrm{~cm} / \mathrm{yr}$ and its value increases with distance from the reference region. It is apparent that the magnitude of the observed ground deformation is similar to the error of measurements. The accuracy might be improved if data covering a longer time period becomes available. Because of lower accuracy the PS results were not used in further modeling and inversion.

\subsection{Mapping Volcanic Deformations}

[19] In order to evaluate the applicability of InSAR for the detection of volcanic deformation in AVF, in Figure 7 we plot maximum vertical displacement that would be produced by a volcanic source (Mogi point source approximation) of various strengths. Each line in Figure 7 correspond to a source located at different depth - 0.5, 1, 4, 4, 8, 16, and $32 \mathrm{~km}$ plotted using a log-log scale in order to capture a large range of source strengths $103-109 \mathrm{~m}^{3}$ (horizontal axis) and a range of observable ground deformation $0.1-100 \mathrm{~cm}$ (vertical axis). It seems that $1 \mathrm{~cm}$ of surface ground deformation is detectable with $\mathrm{C}$-band InSAR in the absence of significant tropospheric noise, which can be produced by sources at various depths depending on their strength. For example, an intruded volume of $107 \mathrm{~m}^{3}$, typical of small AVF eruptions, would be detectable by InSAR at depths less than $15 \mathrm{~km}$, while a volume of $108 \mathrm{~m}^{3}$ should be detectable at much greater depths. Because the Mogi model assumes an elastic media, the detectable depth for $108 \mathrm{~m}^{3}$ is limited by a crustal thickness at approximately $25 \mathrm{~km}$. Finally, in order to provide real-time InSAR detection of magma intrusion, InSAR images would have to be acquired at a three days repeat cycle, assuming a magma ascension rate of $1-10 \mathrm{~cm} / \mathrm{s}$, which is not available under the present satellite configuration. Therefore, detection and monitoring of magma ascent in the AVF region, including estimation of the size and depth of volcanic hazard is possible using current SAR satellite technology and InSAR processing capability, while ascent monitoring would require additional satellite coverage.

\section{Modeling Observed Signal}

[20] The observed ground deformations were inverted in order to derive source parameters and in particular source location, strength and depth using a Mogi point source embedded in an elastic half-space approximation [Mogi, 1958]. The aim of the inversion was to determine if the observed deformations were caused by volcanic activities 
(a) subsidence S1-S3

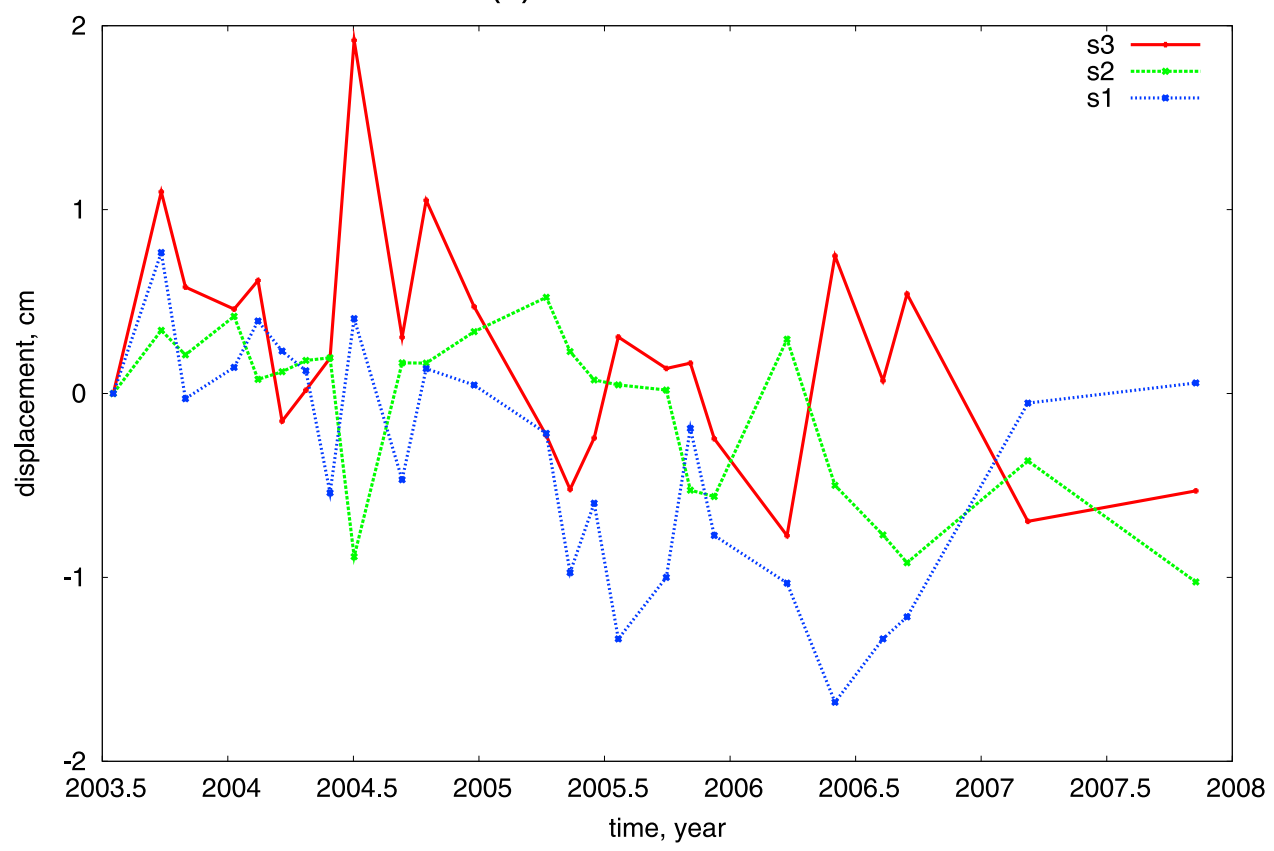

(b) uplift U1-U3

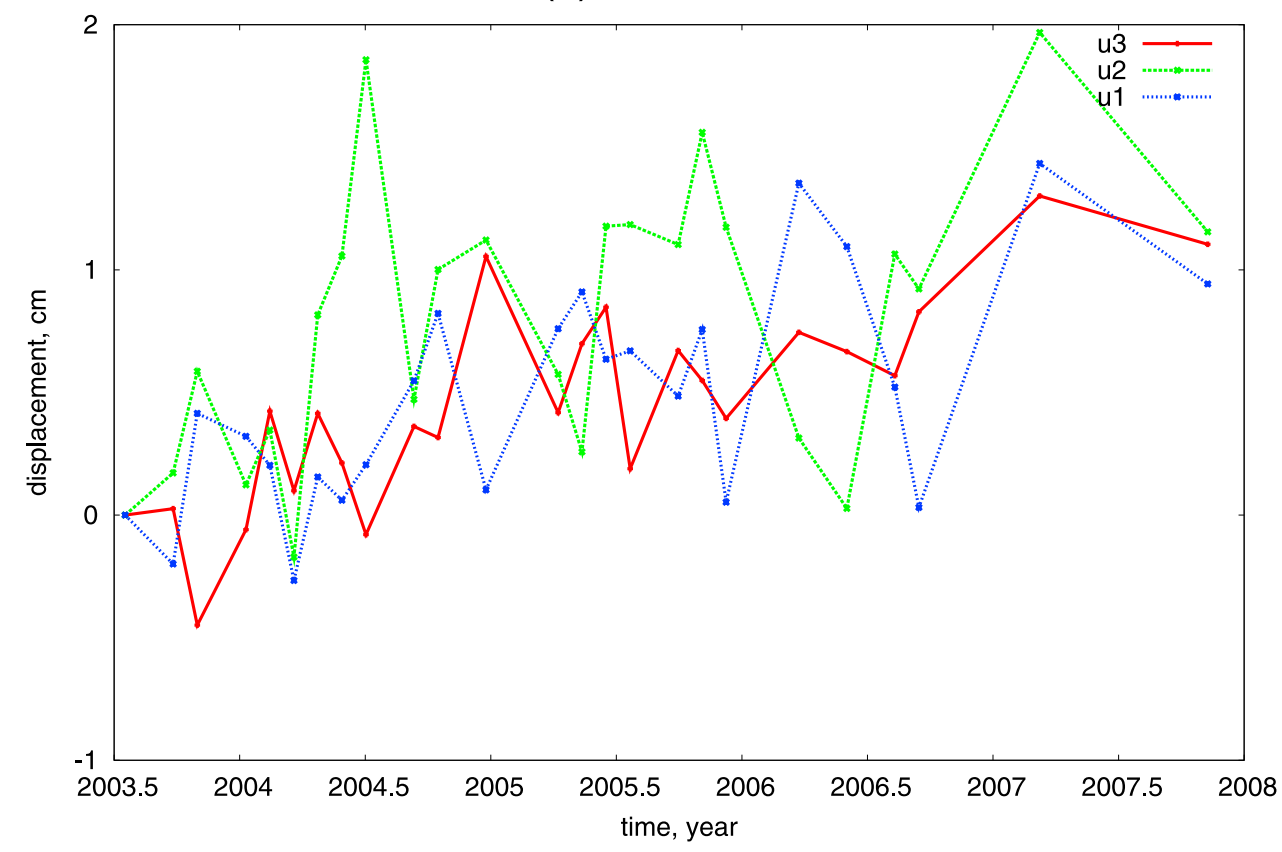

Figure 5. (a) Time series analysis of subsidence s1:(S36.89, E174.63), s2:(S36.94, E174.84) and s3: (S37.03, E174.93) and (b) uplift regions u1:(S36.98, E174.88), u2:(S36.94, E174.66) and u3:(S36.91, E174.69), calculated using SBAS technique. No spatial averaging or temporal filtering was performed on the time series.

or they are anthropogenic, potentially caused by groundwater withdrawal and natural recharge followed the cessation of withdrawal. Because of the spatial extent of the deformation, shallow sources were assumed and a Poisson's ratio of 0.25 and an elastic shear modulus of $10 \mathrm{GPa}$ were chosen, to account for the less compacted and rigid material present at shallower crustal depths. Due to the best spatial coverage and the smallest error only stacking results were used in the inversion. The radial and vertical displacements caused by Mogi-type source are described by the following equations:

$$
u_{r}=\frac{3 a^{3} \Delta P}{4 \mu} \frac{r}{R^{3}}, \quad u_{z}=\frac{3 a^{3} \Delta P}{4 \mu} \frac{d}{R^{3}},
$$



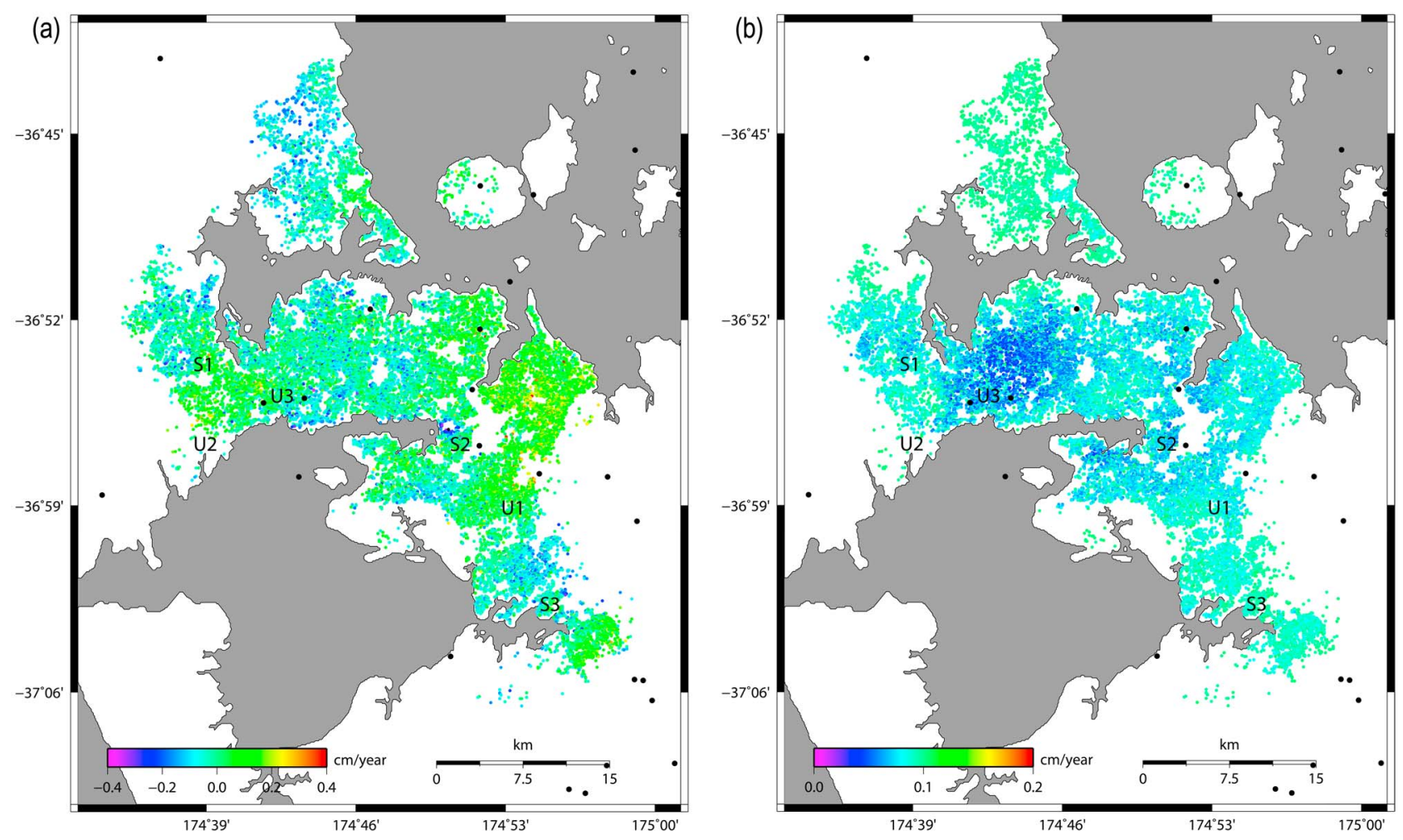

Figure 6. (a) Linear rates of deformation with (b) corresponding errors calculated from 78 differential interferograms with $B p<300 \mathrm{~m}$ acquired by the Envisat satellite between 2003 and 2007 using Permanent Scatterers technique.

where $u_{r}$ and $u_{z}$ are the radial and vertical displacements, $a$ is the source radius and $\Delta P$ is the pressure change, $\mu$ is the shear modulus, $r$ and $d$ are the radial distance of the observation point and source depth. Due to the linear relation between source radius and pressure change in the deformation kernel of the isotropic point source it is possible to measure only the total change of $a^{3} \Delta P$. Instead it was proposed to reformulate the Mogi model according to Tiampo et al.

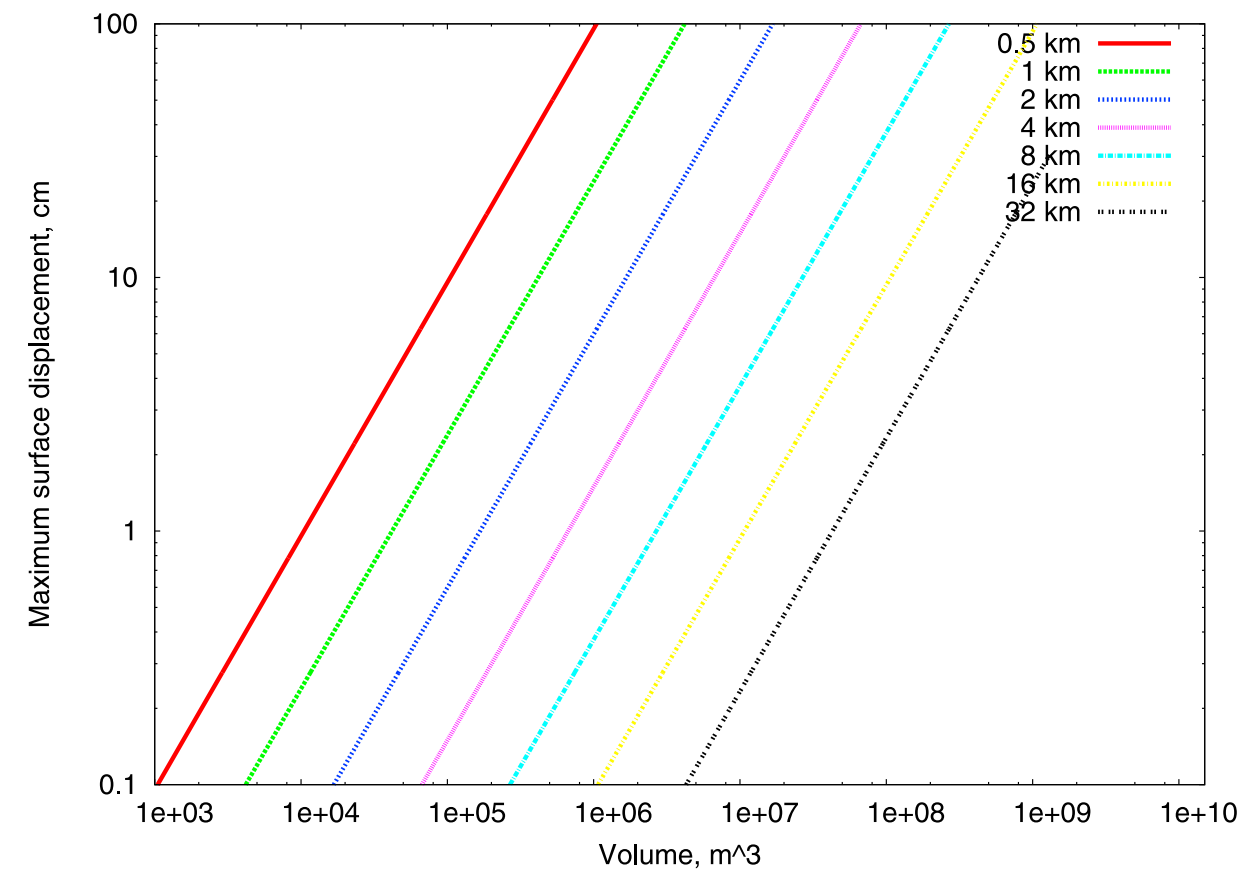

Figure 7. Maximum surface displacement for Mogi-type point sources [Mogi, 1958] due to volume change located at various depths between 0.5 and $32 \mathrm{~km}$. Log-log scale is used. 

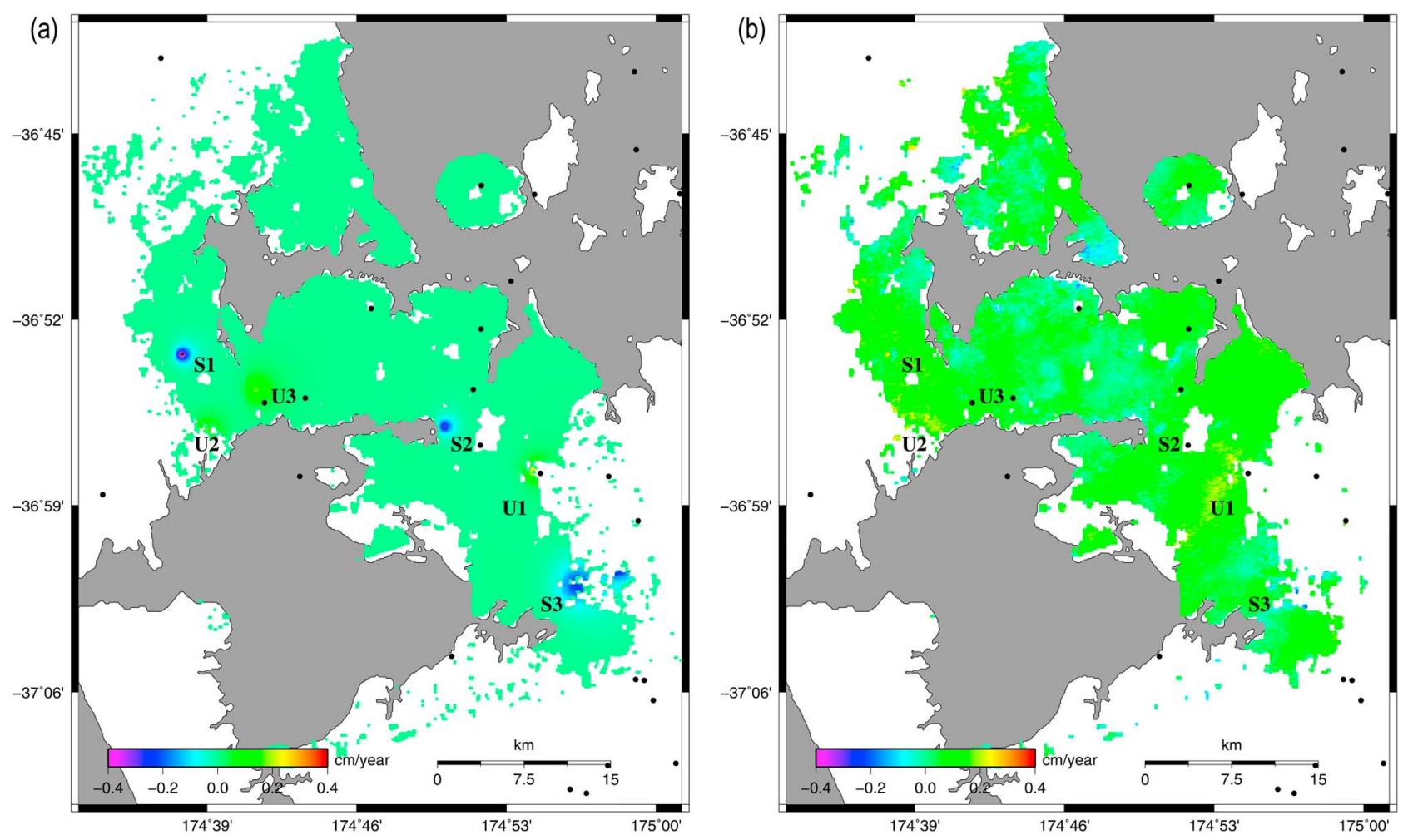

Figure 8. (a) Results of computer modeling and (b) residual signal of deformation rates obtained by stacking, using Mogi point source model and Simulating Annealing plus Simplex optimization algorithms. Earthquakes with maximum magnitude between 1.7 and 3.0 occurring between 1998 and the present are shown as black dots.

[2000] to relate the ground deformation to the source volume change:

$$
u_{r}=\frac{3 \Delta V}{4 \pi} \frac{r}{R^{3}}, \quad u_{z}=\frac{3 \Delta V}{4 \pi} \frac{d}{R^{3}}
$$

where $\Delta V$ is the volume change.

\subsection{Nonlinear Inversion Using the Derivative-Free Simplex Method}

[21] The four model parameters (longitude, latitude, depth and volume change of the source) were estimated by minimizing the misfit function between observed ground deformation calculated by stacking (Figure $3 \mathrm{a}$ ) and values provided by the Mogi model [Mogi, 1958] using the derivative-free simplex method [Nelder and Mead, 1965]. The misfit function used in this study was a common L2-norm (the root square of the sum of square errors, RSSE). The inversion for each source was repeated one hundred times and the average value and standard deviation for each modeled parameter were calculated. This approach allowed us to estimate the accuracy of the inversion. In order to decrease inversion time the following limitations were applied to the modeled parameters: longitude and latitude were bounded to $\pm 1 \mathrm{~km}$ from the center of the surface deformation anomaly, depth varied from 200 to 2000 meters and volume change from 0 to $106 \mathrm{~m}^{3}$ for the uplift signals and 0 to $-106 \mathrm{~m}^{3}$ for the subsidence signals.

[22] The results of this modeling, source location, depth and volume change, are presented in Table 2 and in Figure 8. Three regions of subsidence were modeled by four point sources. Subsidence S1 was modeled as a point source located at depth $451 \mathrm{~m}$ with volume change $-4174 \mathrm{~m}^{3} / \mathrm{yr}$; subsidence S2 was model as a point source located at depth $587 \mathrm{~m}$ with volume change $-3858 \mathrm{~m}^{3} / \mathrm{yr}$; and subsidence $\mathrm{S} 3$ was modeled as two point sources located at depth 715 and $1101 \mathrm{~m}$ with

Table 2. Results of Computer Modeling Using Mogi Point Source Approximation

\begin{tabular}{|c|c|c|c|c|c|c|c|}
\hline Source & Longitude & Latitude & $\operatorname{Easting}^{\mathrm{a}}(\mathrm{km})$ & Northing ${ }^{\mathrm{a}}(\mathrm{km})$ & Depth (m) & Volume Change $\left(\mathrm{m}^{3} / \mathrm{yr}\right)$ & $\operatorname{RMSE}(\mathrm{cm} / \mathrm{yr})$ \\
\hline $\mathrm{S} 1$ & 174.649955 & -36.888961 & $-10.348 \pm 0.001$ & $12.313 \pm 0.001$ & $451 \pm 1$ & $-4174 \pm 1$ & 3.03 \\
\hline $\mathrm{S} 2$ & 174.825482 & -36.934733 & $7.806 \pm 0.199$ & $7.237 \pm 0.318$ & $587 \pm 144$ & $-3859 \pm 1029$ & 3.03 \\
\hline S3 (W) & 174.939379 & -37.021722 & $19.579 \pm 0.005$ & $-2.432 \pm 0.013$ & $715 \pm 3$ & $-13277 \pm 171$ & 4.29 \\
\hline S3 (E) & 174.914592 & -37.033865 & $17.015 \pm 0.064$ & $-3.774 \pm 0.028$ & $1101 \pm 60$ & $-13389 \pm 8778$ & 4.29 \\
\hline U1 & 174.882492 & -36.961938 & $13.701 \pm 0.178$ & $4.211 \pm 0.013$ & $866 \pm 156$ & $7930 \pm 1376$ & 4.32 \\
\hline U2 & 174.670118 & -36.931915 & $-8.261 \pm 0.057$ & $7.549 \pm 0.097$ & $902 \pm 26$ & $4377 \pm 78$ & 2.48 \\
\hline U3 & 174.700367 & -36.910937 & $-5.133 \pm 0.001$ & $9.879 \pm 0.001$ & $926 \pm 1$ & $6834 \pm 1$ & 3.09 \\
\hline
\end{tabular}

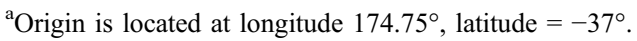




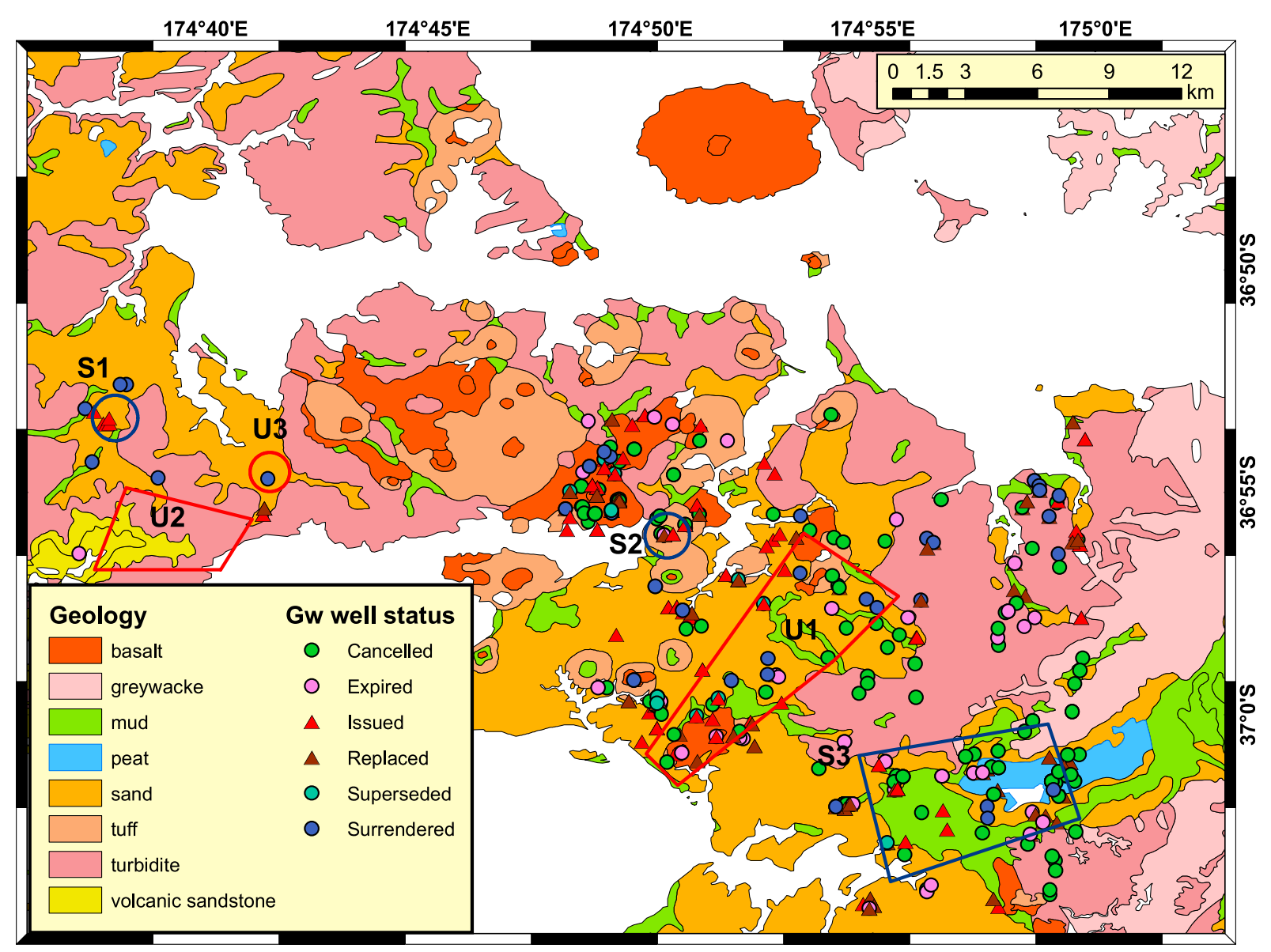

Figure 9. Geological map of Auckland Volcanic Field with locations of known groundwater wells. Regions of deformation are outlined in red (uplift) and blue (subsidence).

volume change -13277 and $-13389 \mathrm{~m}^{3} / \mathrm{yr}$. Three regions of uplift were modeled by three point sources: uplift S1 was modeled as a point source locate at depth $866 \mathrm{~m}$ with volume change $7930 \mathrm{~m}^{3} / \mathrm{yr}$; uplift S2 was modeled as a point source located at depth $902 \mathrm{~m}$ with volume change $4377 \mathrm{~m}^{3} / \mathrm{yr}$; and uplift U3 was modeled as a point source located at depth $926 \mathrm{~m}$ with volume change $6834 \mathrm{~m}^{3} / \mathrm{yr}$. A reasonable accuracy was achieved for sources S1, S3(West), and U3, while the accuracy for other sources was moderately lower (Table 2).

\section{Discussion and Conclusions}

[23] In this work we present ground deformation signals observed at the Auckland Volcanic Field, North Island of New Zealand during 2003-2007. This area is of great importance because of the coincidence of past volcanic activity and modern dense population of over one million in the city of Auckland. At the same time, analysis of past volcanic activity suggests that the magnitude of a new eruption when it occurs will be large.

[24] Over a hundred Envisat interferograms spanning 2003-2007 were calculated and advanced processing was performed. All three techniques (stacking, Small Baseline Subset and Permanent Scatterers) produced average deformation rates with corresponding errors and SBAS and PS techniques also produced time series; however, in this work only the SBAS time series are presented. The interpretation of the observed deformation rates suggests absence of a large deformation signal between 2003 and 2007, but a variety of deformation signals of small spatial extent and magnitude are observed. We concentrated our attention on three uplift regions (marked as U1, U2, and U3 in Figures 3a, $4 \mathrm{a}$, and $6 \mathrm{a}$ ) with approximate rates of $0.4 \mathrm{~cm} / \mathrm{yr}$ and three subsidence regions (marked as $\mathrm{S} 1, \mathrm{~S} 2$, and $\mathrm{S} 3$ in Figures $3 \mathrm{a}$, $4 \mathrm{a}$, and $6 \mathrm{a}$ ) with approximate rates of $-0.4 \mathrm{~cm} / \mathrm{yr}$. In order to determine origin of the observed signal we performed inversion of the ground deformation using a Mogi point source approximation. We determined location, depth, and volume change for each source, which are presented in Table 2. The depth of modeled sources lies between $451 \mathrm{~m}$ (S1) and $1101 \mathrm{~m}$ (U1). Cassidy et al. [1986] estimated that the source of basaltic magma lies at much greater depths of approximately 70-140 km and magma ascent during the observational period would have certainly produced localized seismicity. However, during the 2003-2007 period only a few small earthquakes $(\mathrm{M}<3)$ were observed, and none of them were close to the observed deforming regions. Therefore, due to the lack of evidence for a volcanic or tectonic origin of these deformations it is proposed that they are produced by changes in near-surface groundwater levels: either through extraction or natural recharge.

[25] A geological map of the Auckland Volcanic Field is presented in Figure 9, and outlines of the observed signals 
are plotted in blue (subsidence) and in red (uplift) based on visual analysis of Figure 3a. Locations of known groundwater wells are plotted as triangles for currently operational wells and smaller circles for wells that were active recently but presently abandoned. The groundwater well information for this region is very limited. However, based on the available information, we determined that the location of subsidence S1 precisely coincides with four wells that currently are used for supplying water to a food processing plant. These wells were drilled to a depth of $500 \mathrm{~m}$ (corresponding to the $451 \mathrm{~m}$ determined by our inversion) and have been operational since 2001. The maximum allowed extraction rate for each of these wells is $12000 \mathrm{~m}^{3} / \mathrm{yr}$. Our modeling suggests a volume change of $-4174 \mathrm{~m}^{3} / \mathrm{yr}$, which means that groundwater recharge is not able to supply sufficient amounts of water, causing drops in groundwater levels and consequently ground subsidence. Another groundwater well precisely coincides with the location of subsidence S2. The depth of this well is not know (587 $\mathrm{m}$ according to our modeling) but the maximum allowed extraction rate is $304050 \mathrm{~m}^{3} / \mathrm{yr}$, which is well above the volume change provided by our modeling $\left(-3859 \mathrm{~m}^{3} / \mathrm{yr}\right)$. The larger subsidence S3 can be also explained since it coincides with at least fourteen currently active groundwater wells that have supplied water for agricultural irrigation purposes since the 1980s. It is clear that our modeling with two Mogi point sources located at 715 and $1101 \mathrm{~m}$ and producing volume change -13277 and $-13389 \mathrm{~m}^{3} / \mathrm{yr}$ is only a firstdegree approximation, which can be easily improved based on more precise locations of each groundwater well.

[26] Uplift U1, with a source at a depth $866 \mathrm{~m}$ and producing a volume change of $7930 \mathrm{~m}^{3} / \mathrm{yr}$, according to our model, is probably caused by groundwater recharge, since at least 20 abandoned groundwater wells are located in close proximity to this region. The Mogi point source of the U1 uplift, however, cannot produce the elongated shape of the uplift in SW-NE direction. According to our investigations the uplift U2, whose modeled source is located at a depth of $902 \mathrm{~m}$ and producing a volume change of $4377 \mathrm{~m}^{3} / \mathrm{yr}$ likely is not groundwater related, as there are no (active or abandoned) groundwater wells located in that area. However, according to Figure 1, this region is overlain by steep topography. Therefore, residual topographic noise caused by inaccuraciesin the DEM is the likely source of this artefact. The location of uplift U3, with a source at a depth of $926 \mathrm{~m}$ and a volume change of $6834 \mathrm{~m}^{3} / \mathrm{yr}$, precisely coincides with the abandon groundwater well with a depth $200 \mathrm{~m}$ active since 1996 (according to the records), and recently abandoned (exact date unknown). Its near circular shape and localized extent support this assumption.

[27] Further work is required in order to validate the use of a Mogi model, as well as our choice of elastic modulus; however, these results support the identification of the current deformation patterns in the AVF and the initial estimation of source parameters. In Figure 7 we plot the maximum vertical displacement that would be produced by a volcanic source (Mogi point source approximation) of various strengths and depths. Our work demonstrates that, assuming that the frequency of observations is sufficiently high, InSAR is capable of detecting the scale, rate, and magnitude of ground deformations that would likely accompany magma ascent into the crust, a process that could result in the resumption of volcanic activity beneath New Zealand's largest urban area.

[28] Acknowledgments. We acknowledge the New Zealand GeoNet project and its sponsors EQC, GNS Science and LINZ, for providing data/ images used in this study. This work was also supported by MICINN project PCI2006-A7-0660 and by the Foundation for Research, Science and Technology, New Zealand. We thank the Auckland City council for providing groundwater well data. The authors thank John Beavan and Karen Joyce for their valuable recommendations regarding the manuscript. GMT software was used for plotting of the results and Envisat precise orbits from European Space Agency (CAT1 ID 5196) and the Delft University and SRTM data from the USGS were used in interferometric processing. The work of K.F.T. was supported by an NSERC discovery grant.

\section{References}

Allen, S., and I. Smith (1994), Eruption styles and volcanic hazard in the Auckland Volcanic Field, New Zealand, in Geoscience Reports of Shizuoka University, pp. 5-14, Shizuoka Univ., Shizuoka, Japan.

Berardino, P., G. Fornaro, and R. Lanari (2002), A new algorithm for surface deformation monitoring based on small baseline differential SAR interferograms, IEEE Trans. Geosci. Remote Sens., 40(11), 2375-2383, doi:10.1109/TGRS.2002.803792.

Cassidy, J., and C. Locke (2004), Temporally linked volcanic centres in the Auckland Volcanic Field, N. Z. J. Geol. Geophys., 47, 287-290.

Cassidy, J., C. Locke, and I. Smith (1986), Volcanic hazard in the Auckland region, N. Z. Geol. Surv. Rec., 10, 60-64.

Cassidy, J., C. Locke, C. Miller, and D. Rout (1999), The Auckland volcanic field, New Zealand: Geophysical evidence for its eruption history, in Volcanoes in the Quaternary, edited by C. R. Firth and W. J. McGuire, Geol. Soc. Spec. Publ., 161, 1-10, doi:10.1144/GSL.SP.1999.161.01.02.

Costantini, M. (1998), A novel phase unwrapping method based on network programming, IEEE Trans. Geosci. Remote Sens., 36(3), 813-821, doi: $10.1109 / 36.673674$

Dzurisin, D. (2003), A comprehensive approach to monitoring volcano deformation as a window on the eruption cycle, Rev. Geophys., 41(1), 1001, doi:10.1029/2001RG000107.

Edbrooke, S., C. Mazengarb, and W. Stephenson (2003), Geology and geological hazards of the Auckland urban area, New Zealand, Quat. Int., 103, 3-21, doi:10.1016/S1040-6182(02)00129-5.

Farr, T., and M. Kobrick (2000), Shuttle Radar Topography Mission produces a wealth of data, Eos Trans. $A G U, 81,583$.

Ferretti, A., C. Prati, and F. Rocca (2001), Permanent scatterers in SAR interferometry, IEEE Trans. Geosci. Remote Sens., 39, 8-20, doi: $10.1109 / 36.898661$.

Ferretti, A., F. Novali, R. Burgmann, G. Hilley, and C. Prati (2004), InSAR permanent scatterer analysis reveals ups and downs in San Francisco Bay area, Eos Trans. $A G U, 85(34), 317$, doi:10.1029/2004EO340002.

Hernandez, P., N. Perez, J. Salazar, M. Sato, K. Notsu, and H. Wakita (2000), Soil gas $\mathrm{CO}_{2}, \mathrm{CH}_{4}$, and $\mathrm{H}_{2}$ distribution in and around Las Canadas Caldera, Tenerife, Canary Islands, Spain, J. Volcanol. Geotherm. Res. 103, 425-438, doi:10.1016/S0377-0273(00)00235-3.

Horspool, N., M. Savage, and S. Bannister (2006), Implications for intraplate volcanism and back-arc deformation in northwestern New Zealand, from joint inversion of receiver functions and, surface waves, Geophys. $J$. Int., 166, 1466-1483, doi:10.1111/j.1365-246X.2006.03016.x.

Houghton, B., C. Bonnadonna, C. Gregg, D. Johnston, W. Cousins, J. Cole, and P. DelCarlo (2006), Proximal tephra hazards: Recent eruption studies applied to volcanic risk in the Auckland volcanic field, New Zealand, J. Volcanol. Geotherm. Res., 155, 138-149, doi:10.1016/j. jvolgeores.2006.02.006.

Huang, Y., C. Hawkesworth, P. van Calsteren, I. Smith, and P. Black (1997), Melt generation models for the Auckland volcanic field, New Zealand: Constraints from U-Th isotopes, Earth Planet. Sci. Lett., 149 67-84, doi:10.1016/S0012-821X(97)00064-2.

Johnston, D. M., I. A. Nairn, T. Thordarson, and M. Daly (1997), Assessment for the Auckland volcanic field, Tech. Rep. 79, Auckland Reg. Counc., Auckland, N. Z.

Kermode, L. (1992), Geology of the Auckland Urban Area, Inst. of Geol. and Nucl. Sci. Ltd., Lower Hutt, N. Z.

Kwoun, O., Z. Lu, C. Neal, and C. Wicks (2006), Quiescent deformation of the Aniakchak Caldera, Alaska, mapped by InSAR, Geology, 34(1), 5-8, doi:10.1130/G22015.1.

Lu, Z., D. Mann, J. T. Freymueller, and D. J. Meyer (2000), Synthetic aperture radar interferometry of Okmok volcano, Alaska: Radar observations, J. Geophys. Res., 105(B5), 10,791-10,806, doi:10.1029/2000JB900034. 
Lu, Z., C. Wicks, D. Dzurisin, A. Power, S. Moran, and W. Thatcher (2002), Magmatic inflation at a dormant stratovolcano: 1996-1998 activity at Mount Peulik volcano, Alaska, revealed by satellite radar interferometry, J. Geophys. Res., 107(B7), 2134, doi:10.1029/2001JB000471.

Magill, C., and R. Blong (2005), Volcanic risk ranking for Auckland, New Zealand. I: Methodology and hazard ranking, Bull. Volcanol. 67, 331-339, doi:10.1007/s00445-004-0374-6.

Massonnet, D., and K. Feigl (1998), Radar interferometry and its application to changes in the Earth's surface, Rev. Geophys., 36(4), 441-500, doi:10.1029/97RG03139.

Massonnet, D., P. Briole, and A. Arnaud (1995), Deflation of Mount Etna monitored by spaceborne radar interferometry, Nature, 375, 567-570, doi:10.1038/375567a0.

McNutt, S. R. (1996), Seismic monitoring and eruption forecasting of volcanoes: A review of the state of the art and case histories, in Monitoring and Mitigation of Volcano Hazards, pp. 99-146, Springer, Berlin.

Miller, V., T. Hurst, and J. Beavan (2001), GPS strategies for detecting signs of a new eruption site within a volcanic field, in Cities on Volcanoes 2, edited by C. Stewart, p. 98, GNS Sci, Auckland, New Zealand.

Mogi, K. (1958), Relations between the eruptions of various volcanoes and the deformation of the ground surfaces above them, Bull. Earthquake Res. Inst. Univ. Tokyo, 36(2), 99-134.

Nelder, J., and R. Mead (1965), A simplex method for function minimization, Comput. J., 7, 308-313.

Paton, D., D. Johnston, J. Gough, D. Dowrick, V. Manville, M. Daly, T. Batistich, and L. Baddon (1999), Auckland volcanic risk project: Stage 2, Tech. Rep. 126, Auckland Reg. Counc., Auckland, N. Z.

Press, W. H., S. A. Teukolsky, W. T. Vetterling, and B. P. Flannery (2007), Numerical Recipes in C: The Art of Scientific Computing, 3rd ed., 994 pp., Cambridge Univ. Press, Cambridge, U. K.

Salazar, J., N. Perez, and P. Hernandez (2000), Secular variations of soil $\mathrm{CO}_{2}$ flux levels at the summit cone of Teide volcano, Tenerife, Canary Islands, Eos Trans. $A G U, 81(48)$, Fall Meet. Suppl., Abstract V72C-05.
Samsonov, S. (2010), Topographic correction for ALOS PLASAR interferometry, IEEE Trans. Geosci. Remote Sens., 48(7), 3020-3027, doi:10.1109/TGRS.2010.2043739.

Sandwell, D., and E. Price (1998), Phase gradient approach to stacking interferograms, J. Geophys. Res., 103(B12), 30,183-30,204, doi:10.1029/ 1998JB900008.

Sherburn, S., B. Scott, J. Olsen, and C. Miller (2007), Monitoring seismic precursors to an eruption from the Auckland Volcanic Field, New Zealand, N. Z. J. Geol. Geophys., 50(1), 1-11.

Smith, E., and S. Allen (1993), Volcanic hazards at the Auckland Volcanic Field, technical report, Minist. of Civ. Defense, Auckland, N. Z.

Stern, T., E. Smith, F. Davey, and K. Muirhead (1987), Crustal and upper mantle structure of the northwestern North Island, New Zealand, Geophys. J. R. Astron. Soc., 91, 913-936.

Tiampo, K., J. Rundlea, J. Fernandez, and J. Langbeinc (2000), Spherical and ellipsoidal volcanic sources at Long Valley caldera, California, using a genetic algorithm inversion technique, J. Volcanol. Geotherm. Res., 102(3-4), 189-206, doi:10.1016/S0377-0273(00)00185-2.

Wegmuller, U., and C. Werner (1997), Gamma SAR processor and interferometry software, paper presented at Third ERS Symposium on Space at the Service of Our Environment, Florence, Italy.

Wright, T., B. Parsons, P. England, and E. Fielding (2004), InSAR observations of low slip rates on the major faults of western Tibet, Science, 305, 236-239, doi:10.1126/science.1096388.

P. J. González, Facultad de Matemáticas, Instituto de Astronomia y Geodesia, CSIC-UCM, Plaza de Ciencias, 3, E-28040 Madrid, Spain.

G. Jolly and V. Manville, Wairakei Research Center, GNS Science, 114 Karetoto Rd., Taupo, New Zealand.

S. V. Samsonov and K. F. Tiampo, Department of Earth Sciences, University of Western Ontario, B\&GS Bldg., Rm. 1000E, London, ON N6A 5B7, Canada. (ssamson@uwo.ca) 